\title{
Поморова Д.Р. \\ Влияние отложенных налоговых активов и отложенных налоговых обязательств на финансовое состояние предприятия на примере ПАО «Газпром»
}

Российский экономический университет имени Г. В. Плеханова» Саратовский социально-экономический институт (филиал)

(Россия, Саратов)

doi:10.18411/spc-22-11-2017-26

idsp: 000001:spc-22-11-2017-26

Ввиду того, что за последние годы содержание финансовой отчетности, порядок ее подготовки и представления претерпели значительные изменения, главным из которых является переход во всем мире компаний на МСФО. А пользователям для правильной интерпретации статей бухгалтерского баланса и принятия обоснованных финансовых решений необходимо однозначное понимание финансового анализа хотелось бы оценить влияние отложенных налогов на финансовое состояние предприятия, затрагивая 12 стандарт МСФО «Налоги на прибыль».

Тема сложна и не теряет своей актуальности на протяжении последних нескольких лет. Это связано с тем, что правила признания доходов и расходов в бухгалтерском и налоговом учетах не совпадают, а значит и финансовый результат, в результате чего возникают разницы.

В ПБУ «Учет расчетов по налогу на прибыль» выделяются два вида таких разниц: постоянные и временные. В МСФО 12 «Налоги на прибыль» постоянные разницы не выделяются, а возникают лишь временные. Временные разницы - разницы между балансовой стоимостью актива или обязательства в отчете о финансовом положении и их налоговой базой. В зависимости от характера влияния на налогооблагаемую прибыль либо убыток они подразделяются на:

1. Вычитаемые ( приводят к образованию вычетов, то есть налогового убытка);

2. Налогооблагаемые ( приводят к образованию налогового убытка);

Стоит сразу отметить, что эффект, который возникнет в будущем, от налоговых последствий приводит к возникновению в финансовой отчетности отложенных налоговых обязательств и отложенных налоговых активов. Вычитаемые налоговые разницы приводят к образованию отложенных налоговых активов, а налогооблагаемые временные разницы приводят к образованию отложенных налоговых обязательств.

Отложенные налоговые активы ( ОНА) - это суммы налога на прибыль, возмещаемые в будущих периодах в связи с вычитаемыми временными разницами, а также в связи с переносом на будущий период неиспользованных налоговых убытков и налоговых кредитов.

Формула расчета проста:

ОНА=ВВРх \% ставку, применяемую по налогу на прибыль, где

ВВР- вычитаемая временная разница;

Отложенные налоговые обязательства - это суммы налога на прибыль, подлежащие уплате в будущих периодах в связи с налогооблагаемыми временными разницами.

Формула расчета проста:

ОНА=ВНРх \% ставку, применяемую по налогу на прибыль, где

ВНР-временные налогооблагаемые разницы;

Тем самым, отложенные налоговые активы будут уменьшать прибыль предприятия, а отложенные налоговые обязательства увеличивать. Они отражаются в бухгалтерском балансе и участвуют в финансовом анализе, в расчете чистых активов, оказывают влияние на финансовые показатели деятельности предприятия. Чтобы верно 
оценить финансовое состояние предприятия следует учитывать данные обстоятельства и производить корректировку.

Существует несколько подходов, которые корректируют финансовую отчетность предприятия на сумму отложенных налогов.

Суть первого способа: от финансового результата вычитаются отложенные налоговые активы и прибавляются отложенные налоговые обязательства. Суть второго способа: по аналогичной схеме вычитаются и прибавляются отложенные налоги, но не от финансового результата, а от величины суммы собственного капитала.

Проиллюстрируем данное положение на примере первого подхода к корректировке бухгалтерского баланса на сумму отложенных налогов для целей анализа. Для этого стоит обратиться к Таблица 1.

Таблийа 1

Статьи бухгалтерского баланса ПАО «Газпром»

\begin{tabular}{|c|c|c|c|}
\hline $\begin{array}{c}\text { Статья } \\
\text { бухгалтерского } \\
\text { баланса }\end{array}$ & $\begin{array}{c}\text { Сумма, } \\
\text { млн. рублей, } \\
\text { за 2014 г. }\end{array}$ & $\begin{array}{c}\text { Сумма, } \\
\text { млн.рублей } \\
\text { за 2015 г. }\end{array}$ & $\begin{array}{c}\text { Сумма, } \\
\text { млн. рублей } \\
\text { за 2016 г. }\end{array}$ \\
\hline ОНА & 32927 & 66975 & 76713 \\
\hline Нераспределенная прибыль & 3936832 & 4172472 & 4401046 \\
\hline ОНО & 334312 & 386301 & 476146 \\
\hline
\end{tabular}

Согласно первому методу:

Скорректированная прибыль = нераспределенная прибыль - ОНА + OHO;

Исходя из этого можно оценить совокупное влияние отложенных налогов на прибыль предприятия:

$\mathrm{CB} \mathrm{OH}=((\mathrm{OHO-OНА}) /$ скорректированную прибыль $) \times 100 \%$, где

$\mathrm{CB} \mathrm{OH}-$ совокупное влияние отложенных налогов. Совокупное влияние отложенных налогов на прибыль предприятия за 2014 г. - 2016 г. представлены в Таблице 2. Из представленной информации видно, что величина отложенных налогов существенно влияет на прибыль ПАО «Газпром». Причем в 2014 и 2015 годах изменение влияния величины отложенных налогов изменилось несущественно, всего на $0,01 \%$ произошло уменьшение, но в 2016 году влияние отложенных налогов повысилось на $1,45 \%$.

Таблииа 2

«Результаты, согласно первому методу»

\begin{tabular}{|c|c|c|}
\hline Период & $\begin{array}{c}\text { Скорректированная прибыль, } \\
\text { млн. рублей }\end{array}$ & $\begin{array}{c}\text { Совокупное влияние } \\
\text { отложенных налогов, \% }\end{array}$ \\
\hline за 2014 г. & 4238217 & 7,66 \\
\hline за 2015 г. & 4491798 & 7,65 \\
\hline за 2016 г. & 4800480 & 9,10 \\
\hline
\end{tabular}

Стоит отметить, что данным методом измеряется величина задолженности по налогу на прибыль, которую предприятие должно будет погасить. Отражение отложенного налогового актива приводит к увеличению кредиторской задолженности либо к уменьшению дебиторской задолженности по налогу на прибыль. Отражение отложенного налогового обязательства происходит аналогично, только уменьшается кредиторская задолженность либо увеличивается дебиторская задолженность.

Согласно второму подходу, хотелось бы рассмотреть коэффициент финансовой зависимости, который показывает сколько один рубль собственных средств содержит активов предприятия.

Кфинансовой зависимости = Собственный капитал / Валюта баланса;

Скорректированный Кфз= СК-ОНА +ОНО/ ВБ;

Данные представлены в Таблице 3 . То есть на один рубль собственных средств предприятия приходится 0,74 руб. активов. 
После проведения корректировки - 0,99 руб. активов. Финансовая устойчивость вследствие корректировки отложенными налоговыми активами и обязательствами увеличилась на 0, 25 руб. активов.

Таблица 3

Динамика коэффиичента зависимости ПАО «Газпром» за 2014 г. - 2016 г.

\begin{tabular}{|c|c|c|c|}
\hline Период & $\begin{array}{c}\text { КФ финансовой } \\
\text { зав-сти }\end{array}$ & $\begin{array}{c}\text { Скоррек-ванный КФ } \\
\text { финансовой зав-сти }\end{array}$ & $\begin{array}{c}\text { Динамика } \\
\text { Кчнансовой зав-сти }\end{array}$ \\
\hline за 2014 г. & 0,74 & 0,99 & 0,25 \\
\hline за 2015 г. & 0,72 & 0,74 & 0,02 \\
\hline за 2016 г. & 0,75 & 0,78 & 0,03 \\
\hline
\end{tabular}

По динамике видно, что после корректировки коэффициента устойчивости показатели возрастают. При данном методе отложенные налоги влияют на величину обязательства по налогу на прибыль, увеличивая или уменьшая его величину, тем самым оказывают влияние на финансовый результат:

1. Отражая ОНА, увеличивается обязательство по налогу на прибыль и соответственно уменьшается финансовый результат.

2. Отражая ОНО, уменьшается обязательство по налогу на прибыль и соответственно увеличивается финансовый результат.

Подведя итог, можно сделать вывод, что первый способ больше показывает влияние отложенных налогов на источники формирования капитала, а второй способ на различные коэффициенты задолженности. При оценке существенности влияния отложенных налогов на показатель нераспределенной прибыли необходимо учитывать взаимоисключающее влияние отложенных налоговых активов и отложенных налоговых обязательств.

Отложенные налоги окажут существенное влияние на показатель нераспределенной прибыли только при существенной величине либо отложенного налогового актива, либо отложенного налогового обязательства. При сравнительно одинаковых суммах отложенных налоговых активов и отложенных налоговых обязательств их совокупное влияние будет несущественным.

$$
* * *
$$

1. Приказ Минфина России от 19.11.2002 N 114н (ред. от 06.04.2015) "Об утверждении Положения по бухгалтерскому учету "Учет расчетов по налогу на прибыль организаций" ПБУ 18/02" (Зарегистрировано в Минюсте России 31.12.2002 N 4090)

2. Международный стандарт финансовой отчетности (IAS) 12 "Налоги на прибыль" (введен в действие на территории Российской Федерации Приказом Минфина России от 25.11.2011 N 160н) (ред. от 26.08.2015) (с изм. и доп., вступ. в силу с 01.01.2017)

3. Отчетность ПАО «Газпром» за 2014 г. - 2016 г.

\section{Су Цзин \\ Проблемы формирования заработной платы как фактора социального благополучия: опыт России и Китая}

Владивостокский государственный университет экономики и сервиса (Россия, Владивосток)

doi:10.18411/spc-22-11-2017-27

idsp: 000001:spc-22-11-2017-27

\section{Аннотация}

Статья посвящена важной социально-экономической теме - формированию заработной платы, являющейся основным источником дохода для населения многих стран, включая Россию и Китай. Цель статьи заключается в рассмотрении проблем формирования заработной платы как фактора социального благополучия на опыте России и Китая. Автор затрагивает и теоретические, и практические аспекты этих 